\title{
O cinema de Naomi Kawase e o corpo como matéria fílmica
}

\section{Henrique Codato}

Graduado em Comunicação Social pela Universidade Estadual de Londrina (UEL, 2001), é Mestre em Comunicação pela Universidade de Brasília (UnB, 2004) e em Literatura Comparada pela Universidade de Genebra (Unige - Suíça, 2007). Doutor em Comunicação Social pela Universidade Federal de Minas Gerais (UFMG, 2013), foi bolsista PNPD/Capes (20142018) no Programa de Pós-Graduação em Comunicação da Universidade Federal do Ceará (PPGCOM/UFC), onde atua como professor e pesquisador. Atualmente, é docente do curso de Cinema e Audiovisual da Universidade de Fortaleza (Unifor) e coordenador do Grupo de Pesquisa sobre a Imagem (GPI/Unifor).

E-mail: picega@hotmail.com

\section{Eduardo dos Santos Oliveira}

Graduado em Jornalismo pela Universidade Federal do Ceará (2016); Mestre em Comunicação pela mesma instituição (UFC, 2018), com pesquisa sobre o cinema performativo de Naomi Kawase. Tem experiência na área de Comunicação, com ênfase em Comunicação Audiovisual; e na área de Artes, com ênfase em Crítica das Artes.

E-mail: eduardo.olvr@gmail.com
Resumo: Este ensaio pretende fazer uma visita ao cinema autorreferente da diretora japonesa Naomi Kawase a fim de conhecer um pouco mais sobre as práticas performativas por ela empregadas nas (e com as) imagens. Buscamos entender como, em alguns de seus trabalhos, a cineasta inscreve seu próprio corpo na materialidade do filme, transformando-o também em matéria filmica. A investigação conceitual acionada procura dar ênfase ao que acontece, de maneira particular, na confluência de vozes e de forças que compõem o cinema de Kawase.

Palavras-chave: Cinema; Corpo; Performatividade; Naomi Kawase.

\section{The cinema of Naomi Kawase and the body as filmic matter}

Abstract: This essay is dedicated to the self-referent cinema of the Japanese director Naomi Kawase in order to know a little more about the performative practices she employs in (and with) the images. We seek to understand how she inscribes her own body in the materiality of the film, also turning it into filmic matter. The triggered conceptual investigation seeks to emphasize what happens in the confluence of voices and forces that make up Kawase's cinema.

Keywords: Cinema; Body; Performativity; Naomi Kawase.
"Com o corpo em desconsolo, busco comunicar a todes sobre a partida de Henrique Codato, meu querido amigo, ex-orientador de mestrado e coautor deste texto, no início deste ano. Henrique fez sua passagem poucos meses antes desta publicação.

Tento torcer as palavras, conduzi-las em toda sua multiplicidade de forças, numa alquimia que procura, no limite, tornar possível alguma forma de conforto a nós, colegas, alunes, amigues, companheires, família. Que ofereça um pouco de alento à sua mãe.

Gosto de pensar que Henrique se tornou mais uma das forças que nos ajudará a atravessar este momento e a tantos outros que virão, permanecendo vivo \& ativo em nossas matérias e orações. Em fuga, seguimos." 
Introdução

"De que adianta aventurar-se no desconhecido?"

(Uno Kawase, Em Seus Braços)

No filme Em Seus Braços (Ni Tsutsumarete, 1992), a diretora japonesa Naomi Kawase decide partir em busca de seu pai - e, de certa maneira, também de sua própria identidade - munida de uma máquina filmadora analógica de mão, uma câmera fotográfica e um gravador. A fotografia do filme nos apresenta imagens vacilantes e imprecisas, ocasionalmente superexpostas, marcadas pelo excesso de luz, que tendem ao branco, saturam os referentes e inflamam, junto com o celuloide, a perspectiva da imagem como descrição mimética da realidade. Kawase elaboraria mais tarde, em outras realizações, tais como Nascimento/ Maternidade (Tarachime, 2006) e Vestígio (Shiri, 2012), certa similaridade na inscrição de luz no quadro fílmico. No início de Shara (Sharasojyu, 2003), por exemplo, a luz que invade a tela deteriora mais rapidamente a película e impede que vejamos por completo a interação entre dois garotos, antecipando e sublinhando esteticamente a sensação de desatino e de incompreensão vivida pelo garoto Shun frente ao inexplicável desaparecimento de Kei, seu irmão.

Tal sutil oxidação do cotidiano desponta como uma atualização constante na escritura fílmica de Kawase. Note-se, por exemplo, a sequência de Em Seus Braços em que a diretora, ao visitar uma rua adjacente a um dos domicílios outrora habitados pelo pai, aponta sua filmadora em direção a um ponto do caminho e fabula, em voz off: "No verão de 1968, num dia quente como o de hoje, de ar úmido... Naquele verão, eles aqui". Enquanto (re)memora um passado contingente, a cineasta provoca a oscilação da luz que penetra o obturador com - menear da câmera empunhada em vaivém, testando, assim, a fotossensibilidade da película. $O$ contraste entre a banda sonora e a montagem visual promove certa desestabilização da experiência do espectador. Em contraponto a procedimentos do cinema clássico - no qual o som funcionaria de modo a ancorar a imagem na narrativa - , a cineasta orquestra as ambiências de seu filme a partir dos deslizamentos e dos contrastes entre imagem e som. Estas assincronias e antinomias operam, igualmente, na ordenação dos planos, desvencilhando a matéria do filme do modelo de verossimilhança e acentuando o embate entre o campo e o fora de campo, entre o visível e o invisível. Tal articulação transforma o desacordo em composição e o conflito em formas de figuração, em um processo de busca que se constrói junto com a fabricação, a disposição e o arranjo das imagens e das sonoridades do filme; junto com o espectador.

É por meio do agenciamento entre filmagem e montagem, do jogo espaçotemporal de imagens e sons, que a plasticidade audiovisual de Em Seus Braços emerge como um corpo fílmico cujo intuito não se ajusta ao retrato fiel de um acontecimento, mas cuja potência performativa se completa na relação com os nossos corpos espectadores. Conforme formulação da autora Elena Del Rio (2008) a partir da análise de um conjunto de filmes do realizador Douglas Sirk, "o trabalho de edição é crucial no engendramento de ressonância e dissonância entre corpos que na realidade ocupam tomadas diferentes, porém são reunidos em um único nó afetivo" (DEL RIO, 2008: 54, tradução nossa). Isso dito, é possível supor que Kawase efetiva a fabricação e a organização do princípio de intensidade que irrompe das imagens de seu cinema no processo de ordenamento e (re)combinação do material filmado: seja na justaposição de silhuetas refletidas por um aparelho de televisão, seja no ato de exibir reiteradamente fotografias de seu pai, ou, ainda, por meio da incorporação de uma voz off repleta de interrogativas e hesitações, a cineasta multiplica a heterogeneidade de forças que habitam seu entorno em sua atualização no 
tecido fílmico, construindo, dessa maneira, novas camadas de sentido para o filme (figura 1).

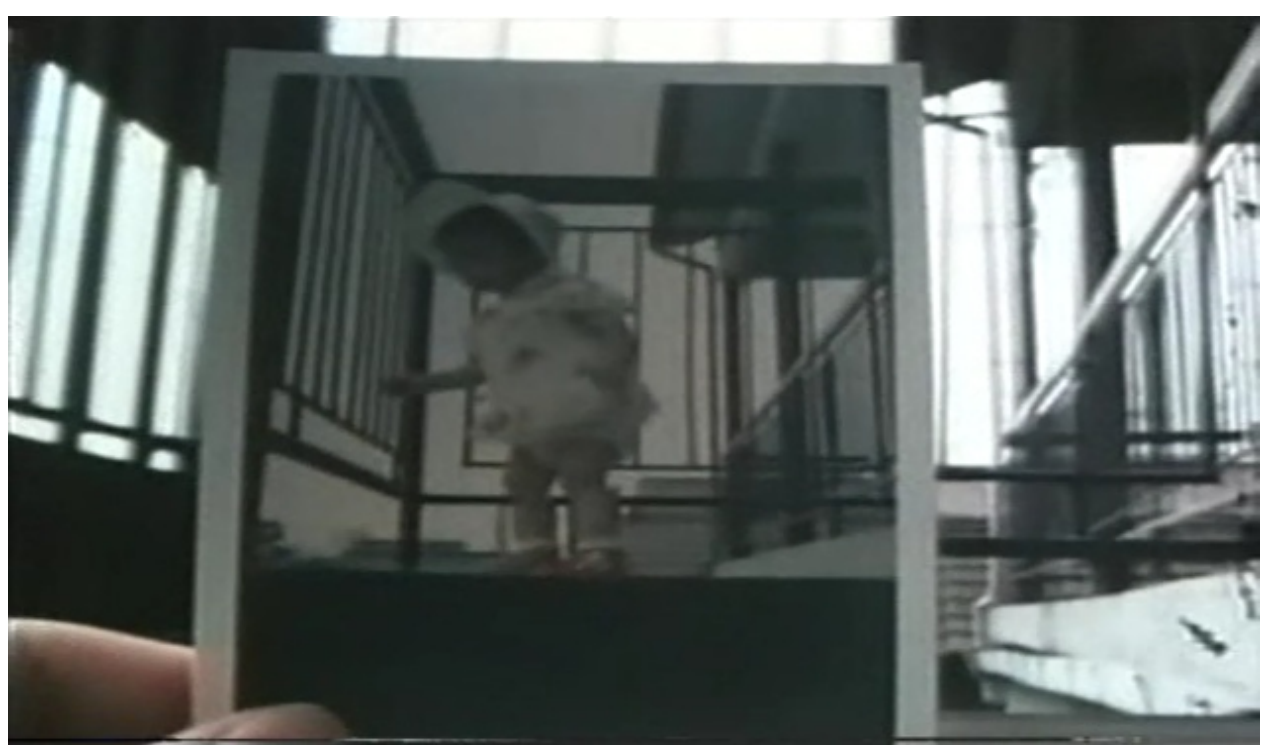

Figura 1. Naomi Kawase entrecruza camadas temporais no tecido fílmico de Em Seus Braços pela ação de (re)visitar antigos locais de sua infância, nos quais algumas fotografias foram tiradas. Com uma mão, a cineasta exibe as fotos e as retira lentamente de quadro, articulando (in)visibilidades e superpondo reminiscências no tempo numa performance agenciada junto à filmagem. 1992 (c) Naomi Kawase, Kumie Inc.

Esta breve descrição de Em Seus Braços já explicita que o exercício de examinar o cinema de Kawase requer que nos situemos em um território movediço e transitório, mas absolutamente original, uma vez que feito do entrelaçamento entre arte e vida. $\mathrm{O}$ que nos instiga no desenvolvimento deste texto é, de maneira precisa, fazer uma visita ao cinema autorreferente da realizadora japonesa a fim

1 De antemão, assinalamos o uso do termo "performatividade" a exemplo de como formula a autora Erika FischerLichte (2008): a performatividade se materializa através de práticas corporais, da performance, apontando para problematizações do corpo para além da linguagem e não para condições preexistentes. Isto é, "a performance é a epítome da performatividade" (FISCHER-LICHTE, 2008: 29). Dito de outro modo, a performatividade é da ordem do devir, do virtual, e encontra na performance uma maneira de atualizar-se, ou seja, tornar-se concretude. de conhecer um pouco mais sobre as práticas performativas ${ }^{1}$ por ela empregadas nas (e com as) imagens; buscar entender como ela inscreve seu próprio corpo na materialidade do filme, transformando-o também em matéria filmica. Assim, de que modo o corpo de Kawase, em seu gesto de autoinscrição na cena, performa diante da câmera? Como o gesto cinematográfico de Kawase promove um entrelaçamento entre cinema e vida? Ainda: como as imagens, articuladas pelo trabalho da montagem, reconduzem nosso olhar pelos filmes? Eis algumas das questões que nos guiam no decorrer deste ensaio.

\section{Um Cinema inclassificável}

Ao mesmo tempo em que os filmes de Naomi Kawase apresentam marcas características da cinematografia japonesa, como o enfoque à vida familiar ou a cadência rarefeita de acontecimentos na narrativa, os procedimentos estéticos por ela utilizados, sobretudo em seus trabalhos autorreferentes, desamarram suas produções de categorizações fundamentadas superficialmente através do prisma de sua nacionalidade.

Nesse sentido, o pesquisador Keiji Kunigami (2011) sinaliza que a diretora vai de encontro aos dois amplos projetos estético-políticos que atualmente ganham espaço no Japão e reverberam de maneira diversa no imaginário global. Um deles, delineado por realizadores como Shinya Tsukamoto (Tetsuo: The Ironman, 1989), Takashi Miike (Audition, 1999 e Ichi, The Killer, 2001) e Kiyoshi Kurosawa (Tokyo Sonata, 2008 e Creepy, 2016), os quais, ainda que de maneiras distintas entre si, produzem obras em torno de disputas no espaço distópico urbano, fazendo referências ao universo da cultura pop japonesa e gozando de sucesso comercial doméstico. Por outro lado, sob outra perspectiva, estão os trabalhos de seus contemporâneos Shinji Aoyama (Eureka, 2000) e de Hirokazu Kore-eda 


\begin{abstract}
2 Aoyama acumula seis indicações em diversas categorias do Festival de Cannes desde 2000, com o lançamento de Eureka. Kore-eda, por sua vez, não só levou dois prêmios do mesmo festival no ano de 2013, mas coleciona mais de trinta e cinco estatuetas de diversas competições internacionais, tais como dos festivais de Veneza e do de São Paulo.
\end{abstract}

3 Também conhecida como "Nuberu Bagu", neologismo baseado no som da expressão francesa Nouvelle Vague tal como pronunciado por um japonês nativo. Trata-se de um cinema feito por jovens cineastas - Nagisa Oshima, Yoshishige Yoshida e Masahiro Shinoda que, em diálogo com o cinema feito na França, neste mesmo momento, tentavam lançar um novo olhar sobre o Japão do pós-guerra.

4 Embora as ideias do autor nos interessem neste trabalho, tendo em vista que consideram o cinema de maneira complexa, imbricado na vida, devemos notar, em seu pensamento, certo "gesto" (sem dúvida político) no sentido de manter acesa uma disputa entre as instâncias do real e do simulacro, tomadas como forças dialéticas.

5 Em entrevista a José Manuel López (2008), a realizadora afirma não observar tanta afinidade entre seu cinema e o de Hirokazu Kore-eda, por exemplo, cujo nome é frequentemente comparado ao de Kawase. Ela explica que reconhece nesse cineasta e em outras figuras como Shinji Aoyama e Nobuhiro Suwa um pensamento teórico deveras lógico e "masculino" acerca do fazer cinema (LÓPEZ, 2008: 142). A isso ela atribui o fato de eles terem adentrado o mundo da criação cinematográfica aprendendo com os realizadores da geração anterior. Ela, por outro lado, teria começado a rodar de forma intuitiva e autônoma. Dessa maneira, por mais que seus filmes encontrem certa correspondência nas obras de Kore-eda (o fotógrafo da maioria de seus filmes, Yutaka Yamazaki, por exemplo, trabalhou em alguns longasmetragens de Kawase), a interlocução entre suas criações não é de todo transparente.
(Nobody Knows, 2004 e After The Storm, 2017), por exemplo, que evidenciam narrativas com particular interesse no cotidiano de seus personagens, recebendo especial atenção da crítica e angariando prêmios dos grandes festivais internacionais ${ }^{2}$. Apesar de algum compromisso com os aspectos tangíveis e virtuais do mundo (referentes históricos, relações sociais e intersubjetivas, por exemplo) se configurarem como interseção entre os projetos citados, as poéticas fílmicas tecidas acerca dessas relações são eminentemente contrastantes.

Kawase, por sua vez, também privilegia o elo sensível com o mundo em suas obras. A cineasta assume o gesto cinematográfico como uma forma de aproximar-se daqueles e daquilo que perpassa seu entorno imediato. Entretanto, sua constante busca por costurar uma identidade fragmentada a partir do paradoxo da onipresença da ausência a impele para outra região de regimes discursivos, situando sua obra "entre um e outro, ou talvez mesmo fora desse paradigma político" (KUNIGAMI, 2011: 192). Se nos trabalhos do primeiro conjunto de realizadores materializa-se efetivamente uma tentativa de elaboração de discursos democratizantes em torno de uma recusa ferrenha à hipocrisia da modernidade, no sentido de desenvolver teses acerca da falência de instituições, tais como a Família e o Estado; nas criações do segundo grupo de diretores, é possível localizarmos certa tendência humanista de esquerda, influência da nouvelle vague japonesa ${ }^{3}$, por exemplo. No cinema autorreferente de Kawase, porém, observa-se uma composição marcada por imagens que saturam demasiadamente seus referentes e, por consequência, a noção de real, lançando suas obras para "longe de qualquer dicotomia, ou campo de batalhas (o simulacro contra o real, o real contra simulacro) ou qualquer modo meramente retórico de fazer falar o 'autêntico'” (Ibid.: 193).

O real na obra de Kawase parece mais relacionar-se com o que é da ordem do fugidio, do descontrole e da instabilidade, tal como propõe Jean-Louis Comolli (2008), do que com o horizonte dos referentes fixos e da imagem como mimese. Segundo Comolli, o real se comporta como uma força arredia que escapa aos regimes de controle, resiste aos mecanismos de roteirização dos quais estamos cercados e burla os holofotes do espetáculo - em nítido diálogo com o pensamento de Guy Debord. O autor, em vista disso, defende a prática documentária como um modo privilegiado de "estar às voltas com a desordem das vidas" (COMOLLI, 2008: 176) e fazer o real irradiar em sua potência de desarranjo das instâncias de "cálculo" e das previsões totalizantes. Propomos um deslocamento da noção de real em Comolli do campo do documentário para a dimensão performativa do gesto cinematográfico de Kawase ${ }^{4}$.

Nesse sentido, a política do cinema de Kawase possui uma qualidade distintiva, mantendo-se distante dos discursos oficiais e das agendas grandiosas, impedindo depreender de seus trabalhos qualquer observação totalizante a respeito do mundo contemporâneo. Isso não significa que devamos reforçar uma pretensa objetividade e adotar uma postura que busca ignorar categoricamente certos trânsitos de vida da cineasta, mesmo a influência primordial de temas da tradição cinematográfica japonesa em sua elaboração estética, desvinculando-a de sua própria obra. Entretanto, seria incoerente, por exemplo, desconsiderar a frequência com que a realizadora destaca-se como a única mulher apontada ao lado de cineastas japoneses homens em textos acerca do cinema contemporâneo produzido no continente asiático ${ }^{5}$.

Dessa maneira, sua nacionalidade não pode ser avultada como tópico que generaliza ou resume sua obra, dado que seu cinema (principalmente o segmento autorreferencial de sua produção audiovisual, o qual nos interessa sobremaneira neste ensaio) é repleto de traços de sua existência, a qual não é capaz de ser sumarizada numa filmografia, mas atravessada pelo seu gesto cinematográfico e 
atualizada junto a esse universo fílmico. Pelo contrário, o que se deseja é corporificar os trabalhos audiovisuais da diretora; isto é, levar em consideração marcas de sua existência no mundo e formular um corpo a partir do material fílmico. Tal gesto corresponde ao profundo entrelaçamento entre corpo, cinema e vida implicado em sua filmografia. Com efeito, a cineasta declarou em entrevista que acredita alinhar-se com determinada cultura visual contemporânea que extrai de suas próprias vivências a matéria prima para a criação de obras:

Meu documentário Em seus braços (Ni Tsutsumarete) foi exibido no Image Forum Festival de 1992. Àquela época, eu percebi que vários realizadores, especialmente mulheres, estavam fazendo documentários sobre as próprias vidas. Até então, a imagem atribuída ao documentário era de filmes sobre temas sociais feitos por grupos de pessoas que se preocupavam com questões similares. Mas recentemente os realizadores têm feito mais filmes sobre si mesmos e seu ambiente mais imediato, não as condições sociais que os cercam. Eu sou uma delas. (KAWASE apud McDONALD, 2006: 246, tradução nossa)

Isso dito, a tarefa de notabilizar este suposto corpo fílmico que aflora das filmagens de Kawase compreende considerá-lo em seu cerne ontológico, na esteira do pensamento de Del Rio (2008): "corpos como criadores, geradores, produtores, performers (grifo nosso) de mundos, de sensações e afetos (...)" (DEL RIO, 2008: 04, tradução nossa). Ainda assim, como propõe Kawase por meio não só de suas criações pessoais, mas de seus trabalhos ficcionais, quando se trata de seu cinema é preciso reiterar a inevitabilidade de afirmar qualquer coisa apenas na medida de sua fugacidade e incompletude. Em outras palavras, o substrato da prática cinematográfica da cineasta não se constitui a partir da perenidade das coisas, mas das ausências e contradições de uma vida em constante processo.

\section{Um cinema atravessado pelo corpo. Um corpo atravessado pelo cinema.}

"Para contar-lhes a razão pela qual comecei a fazer meus próprios filmes, devo remontar a quando tinha 18 anos...", pontua Kawase em entrevista concedida às pesquisadoras Carla Maia e Patrícia Mourão, na ocasião de sua primeira retrospectiva cinematográfica no Brasil (KAWASE, 2011: 16). À época mencionada, em meados dos anos 1980, ainda estudante vinculada à Escola de Artes Visuais de Osaka (Ōsaka Geijutsu Daigaku), a cineasta sairia de casa com sua câmera $8 \mathrm{~mm}$ para filmar "aquilo que a interessava" e formular seu primeiro curta-metragem Eu foco aquilo que me interessa (Watashi ga tsuyoku kyômi o motta mono o ôkiku fix de kiritoru, 1988). Nesse exercício de filmagem, Kawase já enquadrava elementos que seriam mirados outras vezes por sua objetiva ao longo de sua filmografia: o movimento de plantas em contato com o vento, animais não-humanos, objetos descartados no asfalto, rostos de pessoas conhecidas, de estranhos, crianças, idosos, e sua mãe adotiva e tia-avó Uno Kawase. Os planos são ordenados como num inventário, de maneira sequencial e com similar duração, conferindo o mesmo grau de importância a cada matéria filmada. Somente um corpo ainda não aparecia inscrito de maneira visível no campo de filmagem: o da própria cineasta.

Quatro anos mais tarde, após seu primeiro trabalho em $16 \mathrm{~mm}$, intitulado $O$ sorvete do papai (Papa no sofuto kurîmu, 1988), no qual a diretora lançaria mão de procedimentos da ficção para contar certo reencontro entre pai e filha num café, era hora de escavar sua própria história, arriscar-se e enfrentar fantasmas do passado. "Filme o que parece inevitável para você. Algo com o qual terá que se esbarrar", aconselhava seu professor de fotografia (KAWASE apud GEROW, 2008: 115, tradução nossa). Curiosamente, mas não por acaso, em consonância com sua criação ficcional, Kawase logo resolve partir em busca de seu pai 
biológico, o qual nunca conhecera. Um baú de lembranças prestes a ser revolvido e reorganizado na companhia de uma câmera.

Tendo como pista apenas uma antiga fotografia e um par de certidões familiares, a realizadora dá início a uma jornada íntima motivada a princípio pela ausência da figura paterna, mas cujo processo vai revelando uma energia visceral que desestabiliza as perspectivas de identidade da própria cineasta. Essa excursão singular pela topografia de espaços que atravessam sua vida resulta na obra autorreferente Em Seus Braços, filme que inaugura este ensaio e que nos interessa aqui, precisamente, por ser um marco em sua filmografia, emblemático devido à poética de suas imagens e ao seu gesto de autoescrutínio atualizado na imagem, elementos que fundamentarão esteticamente outros de seus trabalhos. Dessa maneira, assimilar certas marcas de sua vida pessoal é também compreender movimentos que são materializados não somente nesse filme, mas na plasticidade de grande parte de sua obra. Dito brevemente, o pai a abandona antes de seu nascimento, e ela é entregue pela mãe aos cuidados dos tios-avós. Kaneichi Kawase, o tio-avô, morre quando Kawase contava 14 anos de idade. A família da garota, então, torna-se uma única pessoa: Uno Kawase, mãe adotiva, tia-avó biológica, a quem Naomi chama resumidamente de oba-san - "avó" em japonês.

A partir desse seu primeiro média-metragem, Kawase, sempre acompanhada por sua câmera, passa a experimentar e explorar com maior grau de complexidade e proximidade aquilo que a interessa, como ao fim de Caracol (Katatsumori, 1994), em que a cineasta adentra o quadro fílmico ao "tocar" o corpo de sua tia-avó através do vidro de uma janela para, logo em seguida, sair da casa e ir tocá-lo "de verdade", passando a ponta dos dedos no rosto da velha senhora enquanto filma (figura 2). "Naomi, não sei como perguntar isso. Você me ama? Você ainda me ama como eu te amo?", ecoa em off na banda sonora, enquanto a realizadora tateia a silhueta de Uno Kawase vista pela vidraça. Parece mesmo haver, nos filmes da diretora, uma tentativa de deter a linguagem (verbal) em nome de uma dimensão muito mais sensível, háptica, tátil e performativa com aquilo que ela enquadra e que vive em seu entorno.

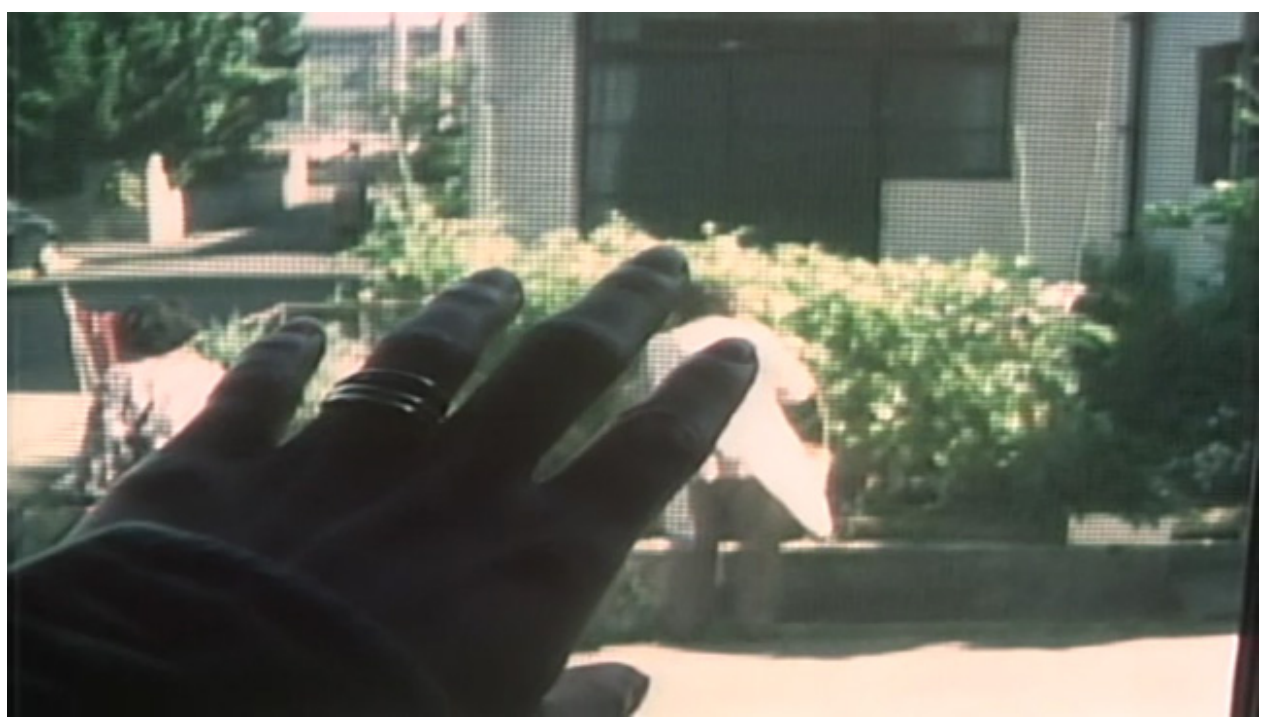

Figura 2. Naomi Kawase reconfigura as dimensões espaciais e corporais de nossa experiência em virtude de sua poética filmica em Caracol, filme no qual admite uma relação performativa com Uno. 1994 @ Naomi Kawase, Kumie Inc.

A convivência com sua tia-avó, ademais, serve de mote para uma sorte de projetos relativos à vida da própria cineasta. Junto com Caracol, Viu o Céu? (Ten, Mitake, 1995) e Sol Poente (Hi wa katabuki, 1996) compõem a chamada "trilogia da avó", espécie de pequena sequência fundamentalmente baseada no estreito 
6 Com exceção de Memória do Vento: Shibuya, 26 de dezembro de 1995 (Kaze no Kioku 1995, 12, 26 Shibuya ni te, 1995), ambientado em Tóquio, Nanayo (Nanayomachi, 2008), na Tailândia, e Koma (Koma, 2009), na Coreia do Sul.

${ }^{7}$ Como em seu filme O Sabor da Vida (An, 2015). Em matéria publicada no periódico Japan Times, o autor Mark Schilling resgata a acepção do realizador e performer japonês Sion Sono acerca do que seria um filme japonês "de verdade" para se referir a essa obra de Naomi Kawase. De acordo com o diretor, em nítido sarcasmo, o cinema que se enquadra nessa categorização volta-se para o público doméstico, especialmente para aquelas pessoas que buscam sair chorando da sala de cinema. Ver: http://www.japanti mes.co.jp/culture/2015/06/03/films/film -reviews/director-naomi-kawase-finallymade-real-japanese-film/\#.WWUdKoTyv IU.

${ }^{8}$ Conforme expomos em seguida, essa parcela compreende as nações asiáticas profundamente influenciadas pela filosofia budista, tais como Tailândia, Japão, China, Mongólia, Vietnã, Índia e Sri Lanka.

9 Também conhecido como "Grande Veículo", o Mahayana se difunde pela Coréia e pelo Japão no século VIII. vínculo entre as duas mulheres, permeada por brincadeiras e performances com a câmera. Anos mais tarde, Kawase haveria de transformar esse relacionamento num confuso e visceral liame, perscrutando a matéria física das duas a caráter quase cirúrgico em Nascimento/Maternidade (Tarachime, 2006), elaborando planos repletos de texturas - de imagens das entranhas do próprio corpo após um parto às rugas que delineiam a pele da forma idosa de Uno. Filmaria também os últimos dias de sua tia-avó em Vestígio (Shiri, 2012), dessa vez em registro digital. Das fronteiras entre o interior e o exterior, o dentro e o fora, o eu e o outro, o passado e o presente, a arte e a vida (e a morte): o cinema de Kawase se localiza, mesmo, no limiar das coisas; entre a superfície (da tela) e a profundidade (da imagem), entre o corpo e o espírito.

Quer seja em curtas ou longas-metragens, ficções roteirizadas ou filmes autoinventivos, seu cinema parece estar intimamente conectado à sua vida e aquilo que a rodeia. Poderia ser feita, nesse momento, referência a Nara, cidade em que nasceu Kawase, a mais antiga do Japão, na qual Kawase roda a maioria de seus filmes ${ }^{6}$. Nas palavras da própria diretora: "Nara é mais do que um mero lugar para mim; tem uma presença tão evidente como minha própria carne e meu próprio sangue. (...) Nara está simplesmente 'ali', é parte integrante de mim mesma" (GEROW in Lopez, 2008: 118). E tal qual faz com o próprio corpo, o cinema de Kawase desmonta e reconstitui seu lugar de origem e seus referentes, complexificando sua efígie e expandindo o conceito de casa. Em outras palavras, mesmo havendo uma ancoragem poética e política no lugar estimado como seu lar, o cinema da diretora é feito de ausências: a fuga, a imprecisão e a evaporação nos quadros demarcam insistentemente uma deriva, apagam as referências em nome dos afetos.

A prática cinematográfica de Kawase está sobremaneira atravessada por diversas marcas de sua existência, a qual é repetidamente atualizada pelo seu universo fílmico e vice-versa. Não se trata, aqui, de defender um pretenso "cinema japonês", sumarizando sua obra com base tão somente em sua nacionalidade - à revelia das demais marcações ético-estéticas de sua filmografia -, mas há de se considerar uma série de elementos da cultura japonesa (a comida, o teatro, as vestimentas, os rituais) que aparecem com frequência nos filmes da diretora ${ }^{7}$. Desse modo, se desejamos evidenciar o corpo produzido pelo material fílmico da cineasta a fim de compreender de que maneiras este corpo pode relacionar-se com quem se põe diante dele, convém refletirmos brevemente acerca de possíveis formas de pensar esse tema no Japão e na cultura japonesa.

Ponderar sobre como o tema do corpo é tratado pelo ocidente em contraste a como ele vem sendo pensado em determinada parcela do oriente asiático ${ }^{8}$ nos leva diretamente à noção de impermanência, bastante cara à tradição e ao pensamento nipônicos. Christine Greiner (2015) explica que as concepções mais antigas de corpo no Japão foram importadas da Índia e da China, especialmente da medicina clássica e do budismo reformado, intitulado Mahayana9. A concepção que nos interessa de impermanência é de origem budista e aponta para a efemeridade da existência e a relação indissolúvel entre o corpo humano, a natureza e o cosmos. A autora indica ainda a importância da mudança e do movimento na vida dos seres vivos, ressaltando um constante estado de "fluxo" nos e dos corpos (GREINER, 2015: 26).

Outro termo japonês que nos remete à poética fílmica de Kawase - e que está inerentemente relacionado ao conceito de impermanência - recebe a alcunha de mono no aware (物の哀れ), ou "pathos das coisas", como é comumente traduzido, e se refere à consciência da fragilidade da existência e do caráter agridoce das transições intrínsecas à vida. De acordo com a professora Tomiko 
${ }^{10}$ Escrito no Japão no início do século XI, em meados da Era Heian, também conhecida como Baixa Antiguidade, $O$ Conto de Genji é considerado um dos primeiros romances literários do mundo. Nele, a autora Murasaki Shikibu, ou Lady Murasaki, dama de companhia da corte, desenvolve uma narrativa ficcional em 54 capítulos a partir das relações aristocráticas do Império Japonês à época, como explica o autor Haruo Shirane (1987).

11 Embora essa afirmativa compreenda o universo fílmico de Naomi Kawase, suas obras O Sabor da Vida e Esplendor (Hikari, 2017) são bastante marcadas por uma linguagem narrativa tradicional, na tentativa de fazer um cinema mais "universalizante", por assim dizer, tanto no sentido quanto na forma. Nesse sentido, a presença deles em sua filmografia tensiona a assertiva.
Yoda (1999), essa nomenclatura aparece pela primeira vez no século XVIII, nos trabalhos de revisão e interpretação do crítico literário Motoori Norinaga acerca da obra seminal $O$ Conto de Genji (源氏物語, Genji Monogatari) ${ }^{10}$, de Murasaki Shikibu, e pode ser tomada como "a força afetiva e estética das coisas do mundo" (YODA, 1999: 524, tradução nossa). Esse entendimento estaria vinculado não somente à literatura, mas ao pensamento filosófico clássico nipônico, influenciando uma sorte de expressões artísticas no Japão. Para o autor Ken Liu (2013), o termo remete à empatia em direção ao inevitável estado passageiro das coisas, contudo sem obliterar a "importância da memória e persistência do passado" (LIU, 2013).

Marcada pelo exercício sensível de autodescoberta e por narrativas rarefeitas, a produção cinematográfica de Kawase parece conversar diretamente com a tradição filosófica japonesa. No entanto, por mais que observemos seguramente certas afinidades entre a poética e a estética de Kawase e um conjunto de teorias associadas ao pensamento japonês, a visceral autoimplicação da cineasta em sua prática cinematográfica a projeta, de novo, para longe de um quadro de realizadores que buscam definir ou retratar o próprio país.

É possível encontrarmos, por outro lado, ecos estilísticos entre a obra de Kawase e a de cineastas de diversas regiões do globo que investigam o "gasoso da imagem", como propõe Camila Vieira da Silva (2009) - isto é, que buscam aquilo que é invisível na imagem, mas que a permeia como arranjo sensorial (SILVA, 2009: 100) -; ou, ainda, construir conexões com trabalhos atravessados por aquilo que parte da crítica tem denominado de "estética do fluxo": filmes que "assumem a construção de um tempo não-linear", marcado por esvaziamentos e plenitudes, na qual os personagens e o espectador estabelecem uma relação sensorial e corpórea com o espaço em que a ação se desenvolve (VIEIRA JR., 2009: 04).

Os "cineastas do fluxo", diria Luiz Carlos Oliveira Jr. (2010), sendo eles Claire Denis, Pedro Costa, Gus Van Sant, Wong Kar-Wai, Tsui Hark, entre outros, não compartilham um modo cristalizado de elaborar planos fílmicos, mas realizam "um cinema de imagens que valem mais por suas modulações do que por seus significados" (OLIVEIRA JR., 2010: 92). Entretanto, por mais que o cinema de Kawase, sobretudo a parcela ficcional de sua filmografia, esteja em consonância com essas asserções, a presença de elementos da natureza em harmonia com o corpo dos personagens de seus filmes a aproxima de diretores "do fluxo" que se distanciam das narrativas eurocentradas ${ }^{11}$, como Hou Hsiao-Hsien, de Taiwan, e Apichatpong Weerasethakul, da Tailândia.

No cinema de Weerasethakul, tal como no de Kawase, existe a proposição de outra forma de apreensão do tempo, em que seu escoamento e suspensão ressaltam um contraste com as narrativas lineares e teleológicas da tradição ocidental. Se compararmos A Floresta dos Lamentos (Mogari no Mori, 2007), da cineasta, a Tio Boonme, Que Pode Recordar Suas Vidas Passadas (Lung Boonmee Raluek Chat, 2010), do tailandês, veremos em comum a comunhão do corpo com a natureza, o fluxo dos corpos em sintonia com o ambiente e a configuração da floresta como mais um personagem da obra. Em certo momento do segundo título, por exemplo, humanos e espíritos partilham de um mesmo espaço cênico sem muitos alardes (não há um salto drástico na intensidade da banda sonora ou trilha a fim de construir uma atmosfera de tensão, por exemplo) e estabelecem uma relação de horizontalidade e interação mútua, do mesmo modo que Shigeki e Machiko, os dois protagonistas do filme de Kawase, se relacionam com o vento, as árvores e os germes. 
Nesse sentido, se considerarmos a impermanência como traço estético em suas estratégias de mise-en-scène, perceberemos a sutileza do embate entre o que se dá a ver e o que se deixa de fora do campo filmado, não necessariamente expresso pelos corpos em cena, mas presente na dimensão sensível dos fluxos rarefeitos dos planos fílmicos em trabalhos ficcionais como Suzaku (Moe no suzaku, 1997) e em Shara. O primeiro, organizado em torno da construção de um túnel no vilarejo de Yoshino, em Nara, e sua concomitância com a dissolução de uma família; e o segundo, mencionado no início deste texto, cujo enredo fundamenta-se na desaparição de um garoto durante um festival de verão na mesma cidade e uma misteriosa chuva que viria oito anos depois do sumiço. Repletos de silêncios, os dois filmes estão impregnados pela dilatação temporal dos planos e o afrouxamento das ações dos corpos dos personagens em cena, em coexistência com movimentos da natureza presentificados de maneira reiterada ao longo das obras, como o forte balanço de árvores em contato com o vento e o som de água que sinalizaria o escoamento do tempo.

Em diálogo com seu cinema ficcional, a cineasta incessantemente faz uso da objetiva como disparador sensível na produção independente de seus filmes autorreflexivos. No caso de Céu, Vento, Fogo, Água, Terra (Kya Ka Ra Ba a, 2001), em estreito diálogo com os procedimentos de Em Seus Braços, sobretudo pelo retorno do tema acerca do abandono afetivo do pai, Kawase revira seu arquivo pessoal, insere gravações de telefonemas e dispara contingências que se concretizariam de outra forma, caso não estivesse acompanhada de uma câmera. A maneira como a diretora articula imagens de troncos de árvores, correntes de ar, labaredas, tempestades e outros elementos naturais neste filme sublinha sua experiência sensível com o que a rodeia, remetendo novamente à noção de que seu corpo estaria ligado de modo inseparável àquilo que o cerca, sempre em fluxo, em sintonia com o ambiente.

No lugar do excesso de drama, a diluição das ações e o descentramento da própria figura. Por meio de jogos de enquadramento, de luz e sombra, de fragmentações e reflexos, a diretora implica o próprio corpo na filmagem tentando investigar marcas e estratégias estéticas que permitam construir outro tipo de mise-en-scène, modulada pelo corporal, impulsionada por práticas performativas e muito mais preocupada com a fabricação de atmosferas sensoriais do que com encadeamentos narrativos. É como se, por meio de seus filmes, obras sempre tão íntimas e pessoais, pudéssemos ver os rastros de uma presença quase fantasmagórica que insistentemente tenta atestar a própria existência e a existência do mundo pelo gesto poético de filmar (figura 3).

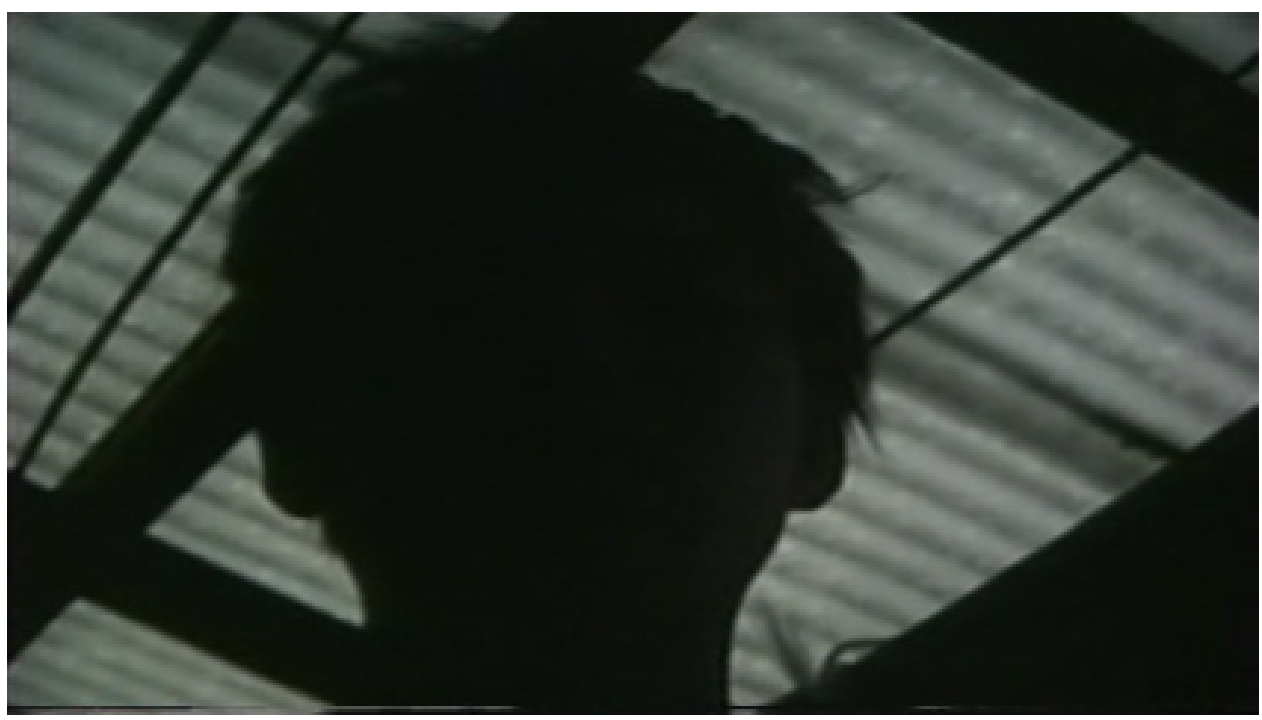

Figura 3. Naomi Kawase empreende diversos jogos com a imagem no filme Em Seus Braços, buscando seus rastros em sombras e reflexos. 1992 (c) Naomi Kawase, Kumie Inc. 
Trata-se de um cinema materializado em virtude de uma urgência pelo viver e pelo sentir. "Eu não gosto da palavra documentário", diz Naomi Kawase durante uma conversa com Kazuo Nishii em Carta de Uma Cerejeira Amarela em Flor declinando o que de acordo com a cineasta se configuraria como práxis de filmes que se adequam a essa denominação: "O termo 'documento' me faz pensar no passado. O documento e o documentário dormem num armazém.", reflete Kawase. Ela, por sua vez, "filma para se sentir viva", estabelecendo uma relação visceral com seu ofício. Essa conexão se desdobra na matéria plástico-figurativa de seus filmes, da presença do corpo da cineasta na cena, e, por conseguinte, na afetação do corpo do espectador.

"Por que as árvores balançam com o vento? Para poderem se tocar. Se eu fosse mais natureza, eu me sentiria muito melhor. Nesse lugar, meu pai deve ter sentido a mesma coisa, eu acho", pondera a cineasta, em outro momento da projeção de Em Seus Braços. Ela mira a filmadora para o chacoalhar da ramagem de uma árvore na tentativa de enquadrar o fluxo eólico, produz uma imagem "de lado", com a objetiva apoiada em alguma área irregular, e insere fotografias suas na montagem. Há, nesse trecho, tal qual na sequência visitada anteriormente, uma reflexão sobre a relação eu-outro, Kawase-Yamashiro (seu pai), atravessada pelas imagens de rajadas e brisas em movimento, do trânsito invisível da natureza que sutilmente transforma as superfícies terrestres, como se a realizadora nos avisasse que todos aqueles corpos filmados (humanos ou não) e materialidades (fotografias de infância, certidões e atestados de sua existência) estão atuando junto a ela em sua busca e performances com a câmera. Em outras palavras: tal como as massas de ar que remodelam a geografia dos espaços de modo (quase) imperceptível, o pai de Kawase está presente em sua obra como força desejante, mesmo ausente, trazendo sua intervenção para o campo múltiplo que é seu cinema.

\section{Conclusão: habitando fronteiras}

Este ensaio buscou mostrar como o conjunto da obra de Naomi Kawase não encontra lugar em classificações que avultam a nacionalidade em detrimento das demais particularidades de sua prática fílmica. Antes disso, o corpo fronteiriço de sua poética cinematográfica parece organizar-se em torno de um limiar estético, distante das narrativas eurocentradas e teleológicas do registro ocidental, mas também à margem do programatismo de diretores que pensam o cinema de maneira demasiadamente lógica, mesmo no extremo oriente asiático. Na mesma perspectiva, cabe dizer que os filmes autorreflexivos da diretora não podem, tampouco, ser considerados documentários propriamente ditos, como sugere a cineasta. Tal elemento corrobora o caráter inclassificável de seu cinema, que não se explica nem pelo viés da nacionalidade nem pela estética ou pelo estilo de filmar.

Quando filma a própria imagem transmitida por um televisor, ou quando põe em quadro a turva sombra de sua silhueta enquanto fabula com a câmera, por exemplo, Kawase libera uma constelação de significados e sensações outrora presos em imagens fabricadas com a intenção de retratar de maneira transparente o outro ou produzir efeitos de verossimilhança sobre um tema. A cineasta, dessa maneira, ocupa um lugar que desafia denominações tradicionais, habitando a fronteira que separaria a vida da arte, o verdadeiro do falso e o cinema das artes visuais. Por esse ângulo, o dualismo sujeito e objeto, por exemplo, estivera sempre associado a outros pares de oposição, tais como dentro e fora, corpo e mente, eu e o outro e forma e conteúdo, afirma Elizabeth Grosz (1994). A autora desenvolve o raciocínio demonstrando que um pensamento apoiado em binarismos necessariamente estabelece hierarquias que afirmam um referente dominante em oposição a outro secundário, que, por sua vez, é 
negativo e complementar ao primeiro. Dessa maneira, essas noções "funcionam implicitamente para definir o corpo em termos não-históricos, naturalistas, organicistas, passivos e inertes, enxergando-o como uma intrusão ou interferência no funcionamento da mente, uma dádiva bruta (...)" (GROSZ, 1994: 3-4, tradução nossa).

Grosz assinala ainda que as matrizes desse pensamento são patriarcais e misóginas, afetando as concepções de razão e política na cultura ocidental. Nesse sentido, talvez, o que a cineasta busque seja fazer-nos encontrar, enquanto espectadores, algo da ordem da sutileza, da delicadeza, como se a superfície fosse a dimensão mais profunda possível a ser alcançada pelo olhar. Quiçá ela também saiba que não podemos acreditar plenamente em nossas lembranças e por isto dê movimento a suas memórias, embaralhando imagens, repertórios corporais e o profundo entrelaçamento entre estes.

Tratamos, enfim, de buscar uma rede de conexões a partir do material plásticofigurativo fabricado por Kawase, especialmente na parcela autorreferente de sua filmografia, e adotar uma postura ético-estética e política diante de seu cinema que procure dialogar com os modos que a própria diretora encontrou para provocar experiências com a imagem. Desse modo, compreendendo a práxis da pesquisa acadêmica como exercício de implicação e risco, afora qualquer anseio por apontar verdades ou representar de maneira universalista algo tomado por objeto. Nas imagens, Kawase toca o próprio rosto e sua sombra acena para ela. Do desejo da artista e do desejo da própria imagem. Dessa maneira, a investigação conceitual acionada neste ensaio procura dar ênfase ao que acontece, de maneira particular, na confluência de vozes e forças que é o cinema de Naomi Kawase.

\section{Referências}

COMOLLI, J. Ver e Poder: A inocência perdida: cinema, televisão, fiç̧ão, documentário. Belo Horizonte: Editora UFMG, 2008.

DEL RÍO, E. Deleuze and the cinemas of performance: Powers of affection. Edimburgo: Edinburgh University Press, 2008.

FISCHER-LICHTE, E. The transformative power of the performance: A new aesthetics. Trad: Saskya Iris Jain. Londres: Routledge, 2008.

GEROW, A. El tema soy yo: Entrevista con Naomi Kawase (1988- 2000). In: LÓPEZ, J. M. (org.). El cine en el umbral. Madrid: T\&B Editores, 2008, pp. 115-134.

GREINER, C. Leituras do corpo no Japão e suas diásporas cognitivas. São Paulo: n1 edições, 2015.

GROSZ, E. Volatile bodies: toward a corporeal feminism. Indianapolis: Indiana University Press, 1994.

KAWASE, N. Algumas notas. In: MAIA, C.; MOURÃO, P. (org.): O cinema de Naomi Kawase. Rio de Janeiro: CCBB RJ, 2011, pp. 16-17

KUNIGAMI, K. Naomi Kawase e o presente. In: MAIA, C.; MOURÃO, P. (org.): $O$ cinema de Naomi Kawase. Rio de Janeiro: CCBB RJ, 2011, pp. 180-195.

LIU, K. Q/A With Ken Liu. Entrevista concedida a Nick Mamatas. Haika Soru. 3/abr2013]. Disponível em: http://www.haikasoru.com/the-future-is- 
japanese/qa-with-ken-liu-and-the-return-of-intern-kathleen/. Acessado em 17/mai/2018.

LOPEZ, J. M. Sólo consigo expressarme a través del cine: Entrevista com Naomi Kawase (2001-2008). In: LÓPEZ, J. M. (org). El cine en el umbral. Madrid: T\&B Editores, 2008, pp. 135-143.

MCDONALD, K. I. Reading a Japanese film: cinema in context. Honolulu: University of Hawai'i Press, 2006.

OLIVEIRA JR., L. C. G. O cinema de fluxo e a mise-en-scène. 2010. 161p. Dissertação (Mestrado em Meios e Processos Audiovisuais) - Escola de Comunicações e Artes, Universidade de São Paulo, São Paulo, 2010.

SHIRANE, H. The bridge of dreams: a poetics of The Tale of Genji. Stanford, California: Stanford University Press, 1987.

SILVA, C. V. Entre a superfície e a profundidade: A câmera-corpo e a estética do fluxo no cinema asiático contemporâneo. In: CONGRESSO BRASILEIRO DE CIÊNCIAS DA COMUNICAÇÃO, XXXII, 2009. Curitiba. Anais [...] São Paulo: Intercom, 2009. Disponível em: http://www.intercom.org.br/papers/nacionais/ 2009/, acessado em 15/jul/2017.

VIEIRA JR, E. O tempo dos corpos no "cinema de fluxo" de Apichatpong Weerasethakul. In: CONGRESSO BRASILEIRO DE CIÊNCIAS DA COMUNICAÇÃO, XXXII, 2009. Curitiba. Anais [...] São Paulo: Intercom, 2009. Disponível em: http://www.intercom.org.br/papers/nacionais/2009/, acessado em 15/jul/201

YODA, T. Fractured dialogues: mono no aware and poetic communication in The Tale of Genji. Harvard Journal of Asiatic Studies, vol. 59, n.2, pp. 523-557, 1999. DOI: https://doi.org/10.2307/2652721 